\title{
Efecto de volumen parcial en la resonancia magnética cardiaca: factor productor de artefactos en la imagen. Video ilustrativo
}

\author{
Partial volume effect in cardiac magnetic resonance imaging: \\ a factor producing image artefacts. Illustrative video
}

\author{
Jorge Ignacio Magaña Reyes, ${ }^{*}$ Francisco Sánchez Lezama, ${ }^{\ddagger}$ Luis Gerardo Domínguez Carrillo§ \\ Citar como: Magaña RJI, Sánchez LF, Domínguez CLG. Efecto de volumen parcial en la resonancia magnética cardiaca: factor productor \\ de artefactos en la imagen. Video ilustrativo. Acta Med Grupo Angeles. 2021; 19 (2): 314. https://dx.doi.org/10.35366/100467
}

Paciente masculino de 67 años de edad, asintomático, que acude referido por médico ecocardiografista por aparente dilatación de la raíz aórtica.

El estudio de la patología del sistema cardiovascular por resonancia magnética cardiaca $(\mathrm{RMC})$ es una de las aplicaciones actuales de diagnóstico que permite observar la anatomía y función del corazón y los grandes vasos. La complejidad de la técnica está dada por: a) la localización y orientación anatómica de las estructuras cardiovasculares, b) las secuencias específicas que se deben emplear, y c) la adquisición de los planos de estudio de acuerdo con la patología cardiovascular estudiada. La orientación del corazón en el tórax condiciona su exploración mediante $\mathrm{RMC}$, pues su eje se localiza en un plano distinto a los ortogonales (axial, coronal y sagital) habitualmente empleados para estudiar el resto de los órganos. En la RMC los planos ortogonales son de gran utilidad para valorar las cardiopatías congénitas, estudiar las masas cardiacas y extracardiacas y evaluar la patología pericárdica. Los planos cardiacos (cuatro cámaras, dos cámaras o eje largo vertical, eje corto, tres cámaras) se emplean para estudiar la patología cardiaca propiamente dicha. Aun cuando se trata de un estudio de enorme valía, no está exento de errores, ya que el denominado "efecto de volumen parcial" puede ocasionar artefactos que pueden llegar a confundir al clínico y al radiólogo no entrenado en RMC. ${ }^{1}$
El efecto de volumen parcial es la pérdida de contraste entre dos tejidos adyacentes en una imagen causada por una resolución insuficiente para que más de un tipo de tejido ocupe el mismo vóxel (o píxel) Video 1: https://www.medigraphic.com/videos/actmed/am212_v1

Eso puede inducir un artefacto de volumen parcial (como se demuestra en el caso presentado) que depende del tamaño del vóxel de la imagen. Si los giros de grasa y agua ocupan el mismo vóxel, sus señales interfieren destructivamente. Una pequeña cantidad de señal de agua puede eliminarse mediante una señal de lípidos más grande del mismo vóxel, lo que da como resultado un vóxel que parece contener sólo lípidos. El efecto de volumen parcial es mínimo con un grosor de corte fino y una resolución suficientemente alta, por lo que es poco probable que la grasa y el agua u otras estructuras diferentes ocupen el mismo vóxel.

\section{REFERENCIAS}

1. Valbuena LS, Hinojar R, Puntmann OV. Resonancia magnética cardiovascular en la práctica cardiológica: una guía concisa para la adquisición de imágenes y la interpretación clínica. Rev Esp Cardiol. 2016; 69: 202-210.

Conflicto de intereses: Los autores no tienen ningún conflicto de intereses.
* Radiólogo. Especialista en Resonancia Magnética Cardiaca. Hospital Villas del Campestre, León, Guanajuato. México.

* Cardiólogo Ecocardiografista. Catedrático de la Facultad de Medicina de León, Universidad de Guanajuato. México.

§specialista en Medicina de Rehabilitación. Catedrático de la Facultad de Medicina de León, Universidad de Guanajuato. México.
Correspondencia:

Dr. Jorge Magaña Reyes

Correo electrónico: magadoc@gmail.com

Aceptado: 29-11-2019.

www.medigraphic.com/actamedica 